\title{
A Religião na História: Leituras Dialéticas
}

Flávio Macedo Pinheiro

\section{Resumo:}

O papel da religião na História pode ser entendido de diversas formas e a partir de diferentes teorias e métodos de estudo. Enquanto forma de entender a realidade proposta notadamente por Hegel, a dialética possibilita uma leitura riquíssima, já que não descarta as contradições entre as manifestações religiosas e a realidade, antes, analisa a religião a partir dessas contradições. Mais do que entender a religião segundo a filosofia hegeliana, serão analisados também desdobramentos dialéticos dessa filosofia segundo dois outros filósofos, a saber, Karl Marx e Walter Benjamin. Ambos empreendem uma análise materialista dialética da realidade e, no caso de Benjamin, sem abrir mão de elementos teológicos.

Palavras-chave: Dialética - Religião - Idealismo - Materialismo - Filosofia Contemporânea 


\section{Introdução}

"No princípio era aquele que é Palavra [Logos]. Ele estava com Deus, e era Deus."

Evangelho segundo João I.I

O papel da religião na História possui inúmeras interpretações, e a relação das diversas manifestações de fé foi, e ainda é, motivo para diversos debates. Desde o princípio, no caso do logos joanino, que serve de epígrafe a essa introdução, a tentativa de entender a religião na História tem sido realizada por vários estudiosos, em especial no mundo ocidental. A título de exemplo, podese discutir a relação entre mito e logos, ainda na Antiguidade Grega, ou mesmo a relação entre razão e fé, na Idade Média e, na modernidade, os campos de atuação da religião e da ciência. Podemos ver uma relação dialética entre tais temas na História, e é justamente esta relação que será estudada no presente trabalho.

Como tal temática exige um recorte mais específico, de uma forma geral veremos a relação dialética entre imanência e transcendência, e tal exposição terá como base as concepções de História encontradas em Hegel, Karl Marx e Walter Benjamin. Esta introdução tem como objetivo fazer uma pequena síntese sobre essa relação, apresentando também os contextos históricos dos três autores que serão trabalhados.

O primeiro versículo do Evangelho de João exprime a ideia de logos como algo divino em si, e conduz à identificação de Cristo como a razão encarnada. Durante a Idade Média, a razão foi vista como algo divino, ponto de interseção entre as esferas celestial e mundana. Esta razão, porém, era de acesso restrito da Igreja, que mediava a relação entre o fiel e o logos. No Renascimento, essa postura começou a ser questionada, cedendo espaço à nova ideia de que a razão é claramente humana, o que possibilitaria então ao homem ter acesso direto a Deus. Isto contribuiu com a Reforma Protestante, onde Lutero, um dos reformadores pioneiros, dava à razão o direito de explicar a Bíblia, defendendo os fundamentos racionais do homem, e trazendo assim, segundo Heine, a liberdade de consciência (I99I, p. 43).

O interesse na razão como ponto focal do valor humano chegou ao auge no Iluminismo do século XVIII, período conhecido como Idade da Razão, por sua confiança no poder do conhecimento humano para superar a injustiça e outras mazelas sociais, atribuídas à "superstição" e à autoridade política arbitrária. O Iluminismo refutou muitos dos pressupostos prevalecentes durante toda a Idade Média, apoiando-se também no racionalismo e no empirismo. Suas características eram o cosmopolitanismo, secularismo, desconfiança das autoridades tradicionais, respeito pela dignidade humana, e convicção de que a razão iluminaria a humanidade e levaria ao perpétuo progresso 
social, político e científico. Um ponto interessante a ser ressaltado é que, no Iluminismo, acontece uma tentativa de separação entre a transcendência e a razão, generalizando-se a primeira em detrimento de uma supervalorização da segunda.

Surge então na Alemanha, no fim do século XVIII, o movimento "Tempestade e Ímpeto" (Sturm und Drang). Este movimento, precursor do Romantismo alemão, foi uma reação contra o racionalismo filosófico, o tumulto social e os artifícios literários da época. O primeiro conceito de História a ser trabalhado está vinculado a esse contexto, que é o de Hegel. O movimento Romântico, que não se restringiu apenas à Alemanha, era uma ramificação do espírito humanista do Iluminismo e também uma reação contra a fé deste último no empirismo e em sua razão "autônoma". Em alguns aspectos, pode-se dizer que há aqui uma tentativa de vinculação da razão à transcendência novamente.

Em meados do século XIX, ocorre na Europa o movimento do Naturalismo, com a tese de que toda a realidade seria natural e nada é, em si, sobrenatural; neste ponto, além da separação entre razão e transcendência, começa uma grande negação da própria existência da segunda. Sua filosofia sustenta que somente o que é suscetível de investigação científica produz conhecimentos úteis. Rejeita a ideia de propósito divino e considera os seres humanos apenas membros do mundo natural. A procura dos "princípios primeiros" da metafísica ou das qualidades essenciais das coisas é inútil, porque o caráter supremo da realidade é intangível. Ramificação do empirismo, o Naturalismo se opõe às opiniões como as do idealismo e do dualismo, que separam o reino da matéria do reino do pensamento; compartilha, com a fenomenologia, a ênfase na experiência direta em detrimento das abstrações mentais e difere do materialismo porque permite a possibilidade de que a realidade talvez não seja puramente física. Marx, o segundo filósofo a ser tratado neste trabalho, está vinculado a esse contexto.

No século XX, num momento onde se questiona até que ponto a ciência pode explicar a sociedade, e a partir das reflexões do pensador Lukacs em relação ao pensamento marxista, despontam vários pensadores no Instituto de Pesquisas Sociais, também chamado Escola de Frankfurt. Aqui se encontra um total repúdio ao determinismo histórico do pensamento marxista predominante, e há também uma grande crítica à afirmação positivista de que os métodos das ciências naturais podem ser aplicados à análise social. Apesar de a transcendência não possuir um papel de destaque na Escola de Frankfurt, o pensador a ser trabalhado - Walter Benjamin - faz este destaque, vinculando as concepções materialistas de Marx com suas concepções teológicas judaicas. 


\section{A Religião na História}

"Aqueles que dizem que Deus não é revelatório não falam de modo algum [do ponto de vista] da religião cristã, pois a religião cristã é chamada a religião revelada. Seu conteúdo é que Deus está revelado para os seres humanos, que eles sabem o que Deus é”.

G. W. F. Hegel

Hegel é um autor de importância axial na história da filosofia ocidental. Sua obra é influente em vários campos, como em filosofia, teoria política e social, estética, filosofia da história, teologia e filosofia da religião. Os outros dois autores a serem tratados possuem seus trabalhos vinculados à filosofia da história de Hegel.

Será tratada aqui a concepção hegeliana sobre religião, porém, tratar qualquer assunto especifico em Hegel não é simples, já que sua obra é vista como uma totalidade sistemática (PLANT, 2000, p. I2), não sendo possível separar a significação e o impacto de seu pensamento religioso de todas as outras áreas de sua obra em filosofia, teoria política, estética e história. Então, a partir da concepção de história hegeliana, será tratada a sua relação com a religião.

Para Hegel, a História não era um ciclo interminável de mudanças, mas uma espiral ascendente que levaria inevitavelmente à condição final do Conhecimento Absoluto. Sua filosofia do "idealismo absoluto (ou dialético)" considerava a história humana uma progressão racional na qual todos os elementos subjetivos do entendimento são purificados, deixando somente o conhecimento puro, objetivo do Absoluto - Deus como pensamento puro ou espírito. Desde seus primeiros escritos, é nítida a relação de Hegel com a filosofia da religião. O conceito de mundo em Hegel é, desde sua raiz, religioso; a sua filosofia é religião que concebe a sua própria essência por meio do pensamento. O mundo é o desdobramento gradual do Absoluto, o ser de Deus não é outro senão o manifesto nesse desdobramento.

A polêmica de Hegel dirige-se contra a separação entre o saber e fé. A tese segundo a qual o autêntico conhecimento filosófico poderia contradizer o conteúdo da fé genuína será diretamente sentida por ele como um pensamento que tem um sabor de blasfêmia a Deus, pois a crença é apenas uma das diferentes formas do saber de Deus. O saber Absoluto não está para além do mundo, não reside numa consciência que Deus tivesse para si, fora do homem; antes, é encontrada completa e absolutamente na consciência humana, que na religião se eleva até a consciência de Deus, e na filosofia até a consciência daquilo que é em verdade esta consciência de Deus. Mas esta é o saber Absoluto, alcançado em virtude de si mesmo e tal como cumpre na consciência humana. A História é o desenvolvimento desse Absoluto, e o conhecimento do mundo é, por necessidade, o conhecimento de Deus. Hegel entende que o direito, a moralidade, o Estado, 
a ética são suas diferentes fases - na verdade contraditórias, mas que voltam a superar toda a oposição - da relação entre o espírito finito e o Absoluto, o que seria, em última instância, outros tantos graus da autorrealização de Deus. Por isso o espírito absoluto - seja arte, culto ou saber puro - é necessariamente religião.

Assim, a imagem total dessa filosofia é plenamente unitária e na grandiosidade da sua concepção muito peculiar. Para onde quer que o homem dirija o seu olhar para conceber filosoficamente, verá em toda parte uma e mesma coisa: Deus. Hegel afirma que quem compreende realmente o mundo, quem o olha filosoficamente, ou seja, quem o examina em sua verdade, deve considerá-lo como um espírito que se tornou visível. Isto porque somente o espiritual é real para ele. De acordo com Hegel, Deus e o homem possuem uma relação dialética íntima que se submete à dinâmica da contradição, própria dela. Esta dinâmica conduz à síntese, quer dizer, à autodissolução do "outro", ao regresso a Deus. Mas o resultado não é, como em toda dialética autêntica, igual ao ponto de partida: Deus conserva-se a Si mesmo no homem. Nisto consiste o seu "conhecer-se a si mesmo". Só então é para si quando no conhecimento do homem se conhece a si mesmo. E visto que a sua realidade consiste no seu ser-para-si, só por meio da mediação do homem Deus será real. Por isso, permutam-se os momentos, e a sua autonomia mútua desmascara-se como uma aparência: Deus também é o finito, e também o homem é infinito. Tal é a fórmula filosófica rigorosa do princípio segundo o qual Deus só é na religião, pois a religião é o saber que o homem tem de Deus.

A intenção filosófica básica de Hegel consiste, portanto, em ver fundada toda a realidade no Absoluto, em conceber tudo como manifestação desse único Absoluto, sendo que há várias formas de se alcançá-lo: esteticamente por meio da arte, na beleza e nas formas materiais; simbolicamente na religião, cuja mais alta manifestação é o cristianismo com seu símbolo central do espírito feito carne; e por meio da razão com a filosofia, o que Hegel vê como a mais alta conquista da humanidade.

\section{O Homem na História}

"O sofrimento religioso é, ao mesmo tempo, expressão de um sofrimento real e protesto contra um sofrimento real. A religião é o suspiro do oprimido, a alma do mundo desalmado, bem como o espírito das condições sem espírito. É o ópio do povo. Abolir a religião, a felicidade ilusória do povo, é reivindicar a sua felicidade verdadeira."

Karl Marx 
A filosofia marxista está vinculada à de Hegel, porém ela começa com uma crítica em relação à anterior. Marx critica a concepção de história hegeliana pelo fato de que nela os homens não agem como sujeitos, já que o posto de sujeito para Hegel, como já foi visto, é ocupado pelo espírito absoluto, ou mesmo por Deus. Para Marx, este pensamento consiste em um injustificado "misticismo". Em oposição a essa ideia, Marx afirmou colocar a filosofia de Hegel que estava do "avesso", ou seja, a visão da realidade em Hegel deveria ser invertida. A realidade deste mundo não deve ser explicada com base em uma realidade divina, mas o ponto de partida do pensamento deve ser a realidade concreta. Este pensamento imprime à filosofia de Marx seu cunho ateísta. Para Marx, portanto, a realidade concreta é a realidade do homem, e sua filosofia é uma filosofia da existência humana. Segundo ele, o homem é originalmente um ser econômico, e suas relações econômicas e particularmente as forças produtivas a elas subjacentes são a base de sua existência. Apenas na medida em que essas relações econômicas se modificam, também se desenvolvem os modos de consciência, que representam a "superestrutura ideológica". Desta superestrutura nascem o Estado, as leis, as ideias, a moral, a arte, a religião e similares. Na base econômica reencontramse também aquelas leis de desenvolvimento histórico, como as que Hegel atribuiu ao espírito. As relações econômicas se desdobram de modo dialético, mais precisamente no conflito das classes. Por isso, para Marx, a História é principalmente a história da luta de classes.

Tanto Marx quanto Hegel acreditavam que a História avança dialeticamente, isto é, por meio de conflitos na ordem predominante, que são resolvidos por intermédio de suas sínteses e se transformam em uma nova ordem que, com o tempo, gera seus próprios conflitos internos e inevitável resolução, e assim por diante. Embora Hegel acreditasse que a consciência humana (ou espírito) fosse a força motriz da História, gerando circunstâncias sociais e materiais, Marx acreditava no oposto: "Não é a consciência que determina a vida; é a vida que determina a consciência", escreveram ele e Engels em A Ideologia Alemã. Diferente de Hegel, como já foi visto, a concepção marxista não admite a existência de nenhum poder divino ou espiritual que governe a História. Tampouco, em última análise, as ideias e os pensamentos dos homens como determinantes para o desenrolar dos acontecimentos.

Para Marx os filósofos apenas interpretam o mundo, mas não tratam de modificá-lo; a partir disso, ele empreende uma crítica de seu tempo. Marx observa que em seus dias a verdadeira essência do homem, sua liberdade e independência, a atividade livre e consciente, não se podem fazer valer. Por toda parte, o homem é tirado de si mesmo e perde suas autênticas possibilidades de existência. Este é o sentido daquilo que Marx chama de "autoalienação" do homem, que significa uma permanente depreciação do mundo. Para Marx, o trabalhador se relaciona com o produto do seu trabalho como um objeto 
alheio, e da mesma maneira na religião, pois quanto mais o homem se põe em Deus, tanto menos retém a si mesmo. Quando o trabalhador coloca sua vida no objeto, ela deixa de pertencer a ele, passando a ser do objeto. Ele não é o que é o produto do seu trabalho. Portanto, quão maior este produto, tanto menor ele mesmo é. Segundo este aspecto, o trabalhador se torna um servo do seu objeto.

Essa atividade atua sobre o indivíduo, assim como a religião na imaginação humana, ou seja, independente deste, já que atua como uma atividade alheia, divina ou diabólica, e assim também a atividade do trabalhador não é a sua autoatividade. Como pertence a outro, ela é a perda de si mesmo. Marx chama isto de trabalho alienado, e o explica a partir de uma comparação entre o animal e o homem (MARX, I983, p. I56). Ele analisa que o animal é imediatamente um com sua atividade vital, que não se distingue dela e, consequentemente, o animal é ela. A atividade vital consciente distingue o homem imediatamente da atividade vital do animal. O trabalho alienado inverte a relação de maneira que o homem faz da sua atividade vital, da sua essência, apenas um meio para a sua existência. O trabalho alienado faz do homem um ser alheio a ele mesmo; aliena do homem o seu próprio corpo, tal como a natureza fora dele, tal como a sua essência espiritual, a sua essência humana.

Toda a autoalienação do homem de si e da natureza aparece na relação que ele confere a si e à natureza com os outros homens diferentes dele. Daí que a autoalienação religiosa apareça necessariamente na relação do leigo com o sacerdote ou também, já que se trata do mundo intelectual, com um mediador. No mundo efetivo, prática e autoalienação só podem aparecer por meio da relação efetivamente real, prática com outros homens.

Religião, família, Estado, direito, moral, ciência, arte etc. são apenas modos particulares de produção e caem sob a sua lei geral. A superação da propriedade privada, enquanto apropriação da vida humana,é, para Marx, a superação de toda a alienação e, portanto, é o retorno do homem desde religião, família, Estado etc. à sua existência humana, isto é, social. A alienação religiosa, como já foi visto, se desenrola no terreno da consciência, do interior do homem, mas a alienação econômica é a vida efetivamente real - a sua superação abrange, por conseguinte, ambos os lados. Daí a insistência do comunismo marxista com o ateísmo.

De acordo com Marx, na sociedade comunista o homem e a natureza serão suas essências, na medida em que o homem se tornaria prática e sensorialmente perceptível para o próprio homem como existência da natureza, e igualmente a natureza para o homem como existência do homem. Tornaria praticamente impossível a pergunta por um ser alheio, por um ser acima da natureza e do homem. O próprio ateísmo não teria mais sentido, pois ele só existe como uma negação de Deus para se afirmar a existência do homem; mas o socialismo não precisa dessas mediações, já que começaria com a consciência da essência 
do homem e da natureza. O socialismo seria também como a representação da autoconsciência do homem, não mais mediada pela superação da religião nem pela superação da propriedade privada, já que, no comunismo, a vida efetivamente real seria a realidade efetiva do homem. O comunismo é então, para Marx, necessário ao desenvolvimento histórico seguinte, da emancipação e recuperação dos homens. É o princípio dinâmico do futuro, mas não a meta do desenvolvimento humano.

A ideia de Marx, portanto, sempre foi procurar uma maneira científica de descrever as relações sociais. Dessa forma, ele pretendia refutar o conhecimento religioso, que por se basear na fé, que é algo metafísico, não pode ser verificado empiricamente. Marx entende também que a religião é um forte instrumento ideológico usado pela burguesia que mantém o pobre/oprimido em seu sofrimento, sem alterar ou transformar a sua realidade. E como já foi visto, a religião é fruto da alienação, não sendo ela a causa dos problemas, mas sim sintoma deles; sintomas esses que desaparecerão quando a verdadeira causa dos problemas, a expropriação da classe proletária, for resolvida.

\title{
IV. A Religião na História do Homem
}

\begin{abstract}
"Eu nunca pude pesquisar ou pensar senão num sentido, se me atrevo a dizê-lo, teológico - isto é, de acordo com a doutrina talmúdica dos 49 níveis de sentido de cada passagem da Torá."
\end{abstract}

Walter Benjamin

Benjamin encontra-se lançado no interior de várias correntes de pensamento. O conflito mais significativo é certamente o que opõe o interesse de Benjamin pela teologia judaica à sua teoria materialista, que é uma releitura do marxismo a partir de uma retomada do pensamento de Hegel. Ele se opõe à esquerda dos movimentos estudantis, ainda que partilhando de suas críticas à sociedade burguesa; ao mesmo tempo, mantém longas discussões com seu amigo Gershom Scholem sobre a teologia e a mística judaicas, e se mostra como um adversário resoluto do sionismo. Suas hesitações irão se manifestar durante toda a vida por meio dessa dupla relação entre o marxismo e o judaísmo. Ao mesmo tempo, essas hesitações testemunham com um senso agudo os perigos em que incorre um movimento político, ao querer realizar a qualquer preço aquilo que define o objetivo último de sua luta: a sociedade sem classes ou a Nova Jerusalém. Benjamin suspeita dessa coincidência precipitada entre o "real" e o "utópico", que faz esquecer a dimensão crítica da ação política, a única, segundo ele, a justificá-la. Em outras palavras, ele se recusa a pensar que o Reino de Deus deva se concretizar na terra. No pequeno texto Fragmento 
Teológico-Político, datado dos anos I920-2I, ele recorre a essa figura do Reino para justamente criticar as correntes judaicas e sionistas de esquerda que, após a instauração da República de Weimar em I9I8, atribuíam às lutas revolucionárias um potencial escatológico.

Retomando os temas da mística judaica, que conhecia por meio de Scholem, Benjamin entende que somente o próprio Messias perfaz todo o acontecimento histórico e, precisamente, no sentido que só ele redime, completa, cria a sua ligação ao próprio elemento messiânico. Daí que o Reino de Deus não pode ser o telos da dinâmica histórica. Benjamin insiste, portanto, na manutenção necessária de uma distância entre a ordem do político e a ordem transcendental da reflexão teológica (judaica) ou crítica (marxista), mesmo que essas duas sejam concebidas conjuntamente para ele.

A frase de Benjamin citada no início dessa análise, segundo Gagnebin (I982, pp.39-40), é muitas vezes vista indevidamente como uma profissão de fé. $\mathrm{Na}$ realidade, essa frase ressalta a ligação dele não aos dogmas da religião judaica, e sim a um modelo de leitura herdado da leitura dos textos sagrados. $\mathrm{Na}$ tradição teológica judaica, e especialmente na tradição mística da Cabala, a interpretação não pretende delimitar um sentido unívoco e definitivo; ao contrário, o respeito pela origem divina do texto impede sua cristalização e sua redução a um significado único. A valorização da teologia judaica nas Teses sobre conceito de História de Benjamin era uma forma de romper com uma visão da História como um contínuo linear e homogêneo (KOTHE, I985, p. I6). Isto se voltava contra o historicismo, principalmente contra o otimismo da socialdemocracia, com a crença de que por ser a História um contínuo linear, haveria um progresso contínuo e que, portanto, de um jeito ou de outro, sem que nada se precisasse fazer, automaticamente se estaria navegando a favor da corrente da História. Para Benjamin, isso acabava não sendo mais do que um tipo de conformismo, um conservadorismo sob a aparência de um espírito progressista, uma ideologia da classe dominante adotada pelo proletariado.

Benjamin dimensiona o interesse de História como recurso hermenêutico e, nesse sentido, ele é profundamente fiel à concepção de História que predomina na tradição judaica, segundo a qual a História possui uma verdade a oferecer e, portanto, tem o seu lugar no interior da teologia e da filosofia. Nota-se que ele não pretendia continuar a escrever história dentro de uma perspectiva historicista, e com acréscimo de alguns dados da esfera econômica. Para Benjamin, tratava-se de uma revolução metodológica e também do modo de fazer exposição. Assim, a historiografia assumia conscientemente o papel de uma práxis política do presente.

Scholem define as ideias de Benjamim da seguinte forma: "Suas opiniões são as de um teólogo abandonado no reino profano" (I994, p. I98), algo como uma "teologia material". A concepção de História para Benjamin, portanto, é o 
resultado dialético entre a sua interpretação das teorias de Marx e o messianismo da teologia judaica. $\mathrm{O}$ aspecto de que o passado possa ser atingido pelo presente do historiador, constitui a "aura" desse resultado dialético. Isto implica uma visão messiânica da História, não meramente no sentido da vinda de um determinado Messias, mas que cada momento da História que conseguisse captar e realmente entender um outro momento da História significaria, em suma, que havia como que uma predestinação naquele momento do passado para que ele viesse a ser entendido neste outro momento do "futuro", mesmo que ele não soubesse quando nem como seria o momento.

\section{Considerações Finais}

"Você pode ser a favor de Deus ou contra Deus, mas não pode ser sem Deus."

Elie Wiesel

Após a exposição desses três autores e, na medida do possível, uma relação com suas concepções de História e religião, pode-se notar a seguinte relação dialética: Hegel vê a História como uma manifestação contínua de Deus; Marx, ao contrário, apresenta a História unicamente como dos homens e consequentemente, de suas relações e conflitos; e por fim Benjamin entende a História como sendo das relações entre os homens, porém com a participação, senão de Deus diretamente - como em Hegel -, de uma ação mística transcendente. Pode-se inferir que a filosofia de Benjamin resulta da contradição dialética entre as filosofias de Hegel e Marx.

Com essas análises, pode-se notar também uma relação dialética entre a razão e a religião, sendo que esta relação possui diferentes resultados de acordo com seu momento histórico. A partir da Antiguidade e passando pela Idade Média, a religião foi predominante nesse resultado; do Renascimento até o Romantismo, a religião e a razão passaram a ter espaços quase que equivalentes; e do Naturalismo até os dias atuais a razão passou a ser predominante. Essa relação fica clara pelo fato de que, mesmo hoje, é muito difícil falar de um desses aspectos sem no mínimo ressaltar a posição do outro, suas relações contraditórias, ou seja, tratar de religião sem discutir os parâmetros da razão, ou discutir a razão sem lembrar qualquer aspecto transcendente, seja para negá-lo ou sustentá-lo.

Paul Tillich, teólogo e filósofo alemão do século XX, apontando as novas relações entre razão, religião e História na contemporaneidade, faz uma interessante afirmação. Denominando a razão por logos, e a História, a temporalidade de kairos (algo como "o tempo certo", "momento que faz sentido"), este relato, que, de certa forma, corrobora a proposta de leituras dialéticas desse trabalho, também a ele servirá de encerramento: 
Assim como os gregos se devotaram à filosofia, obedientes ao logos dentro dos limites do kairos; assim como a Idade Média subordinava o logos ao grande kairos sobre o qual construía sua cultura; assim como a filosofia moderna por meio de seu kairos, adaptou-se ao logos de uma ciência e de uma técnica dominadoras do mundo, assim também a nossa tarefa consiste em servir ao logos a partir das profundezas de nosso novo kairos, agora emergente dentre as crises e catástrofes de nossa época" (TILLIGH, I992, p. 45).

\section{Referências Bibliográficas}

ALVES, Rubem. O que é Religião. São Paulo: Editora Brasiliense, I98I.

BENJAMIN, Walter. Sobre o conceito de história. In: Magia e técnica, arte e política: Ensaios sobre literatura e história da cultura. São Paulo: Editora Brasiliense, I985.

GAGNEBIN, Jeanne Marie. Walter Benjamin: os cacos da história. São Paulo: Brasiliense, I982.

HARTMANN, Nicolai. A filosofia do idealismo alemão. Lisboa: Fundação Calouste Gulbenkian, I983.

HEGEL, Georg Wilhelm Friedrich. A Razão na História: Introdução à Filosofia da História Universal. Lisboa: Edições 70, I995.

HEINE, Heinrich. Contribuição à história da religião e filosofia na Alemanha. São Paulo: Iluminuras, I99I.

KOTHE, Flávio R. (Org.). Walter Benjamin: Sociologia. São Paulo: Editora Ática, I985.

LAGES, Susana Kampff. Walter Benjamin: tradução e melancolia. São Paulo: Edusp, 2002.

MARX, Karl. “A consciência revolucionária da história”. In: FERNANDES, Florestan (Org.). K. Marx, F. Engels: História. São Paulo: Ática, I983.

PLANT, Raymond. Hegel: sobre filosofia e religião. São Paulo: Editora Unesp, 2000 . 
SCHOLEM, Gershom. O Golem, Benjamin, Buber e outros justos: Judaica I. São Paulo: Editora Perspectiva, I994.

Walter Benjamin: a história de uma amizade. São Paulo: Editora Perspectiva, I989.

TILlICH, Paul. "Religião e história". In: A era protestante. São Paulo: Giências da Religião, I992.

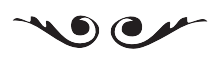

Flávio Macedo Pinheiro é graduando em Filosofia pela USP.

E-mail: flavio.pinheiro@usp.br 